\title{
A serpiginous lesion of scrotum
}

\author{
Sara Romano ${ }^{1 *}\left(\mathbb{D}\right.$, Roberto Dall'Amico², Valentina Declich² and Egidio Barbi ${ }^{1,3}$
}

\begin{abstract}
Background: Median raphe cyst is usually benign and asymptomatic male genitalia lesions. Although uncommon, infection may be a complication.

Case presentation: We report the case of a 4-year-old child presented to the emergency department for a serpiginous and redness lesion extended from the basis of the penis until the perineum. An infected median raphe cyst was suspected, and the patient underwent surgical treatment and antibiotic therapy with complete resolution of symptoms. Liquid culture resulted positive for Serratia Marcescens.

Conclusion: Infection is a rare complication, especially in childhood. To prevent relapses and clinical symptoms, the majority of authors recommend surgical excision followed by primary closure. In case of infections caused by Serratia Marcescens, chronic granulomatous disease should always be rule out.
\end{abstract}

Keywords: Child, Scrotum, Scrotal raphe cyst, Infection, Serratia marcescens

\section{Background}

Median raphe cysts are an embryologic fusion abnormality of the male genitalia that develop along the median penile raphe from the meatus to the perineum [1]. Their clinical presentation is usually in the form of a watery solitary cyst, multiple cysts, or canal-like lesions in the ventral midline part of the penis and perineum [2]. Their diagnosis in childhood is rare, probably because up to $75 \%$ of cases are asymptomatic [2-4]. Therefore, patients often present during second to third decades of life [5]. Infection, rupture, and sexual interference are the most common complications [4].

We present the case of a child with an infected median raphe cyst who underwent surgical and antibiotic treatment with complete resolution of symptoms. Infection is a rare complication, especially in children. This is the first case described in literature in which the culture isolated a microorganism more commonly responsible of infections in patients affected by immunodeficiencies.

\footnotetext{
*Correspondence: sara.romano17@gmail.com

${ }^{1}$ Dipartimento Di Scienze Mediche e Chirurgiche e Della Salute, Università Degli Studi Di Trieste, Trieste, Italy
}

Full list of author information is available at the end of the article

\section{Case presentation}

A 4-year-old-boy presented to the emergency department for a four-day history of discomfort during peeing. The urine analysis was normal. No fever was detected. Past medical and family history were no significant. The clinical examination of genitals showed a serpiginous and redness lesion extended from the basis of the penis and scrotum all along the midline until the perineum (Fig. 1). It was mostly tender and painful to palpation. An empirical broad spectrum antibiotic therapy with oral amoxicillin/clavulanic acid at a dosage of $80 \mathrm{mg} / \mathrm{kg}$ and topical tobramycin was started. The day after the child complained of severe pain of the scrotal region with worsened redness and swelling and pus discharge (Fig. 2). An ultrasound scan showed thickening and hypo echogenicity of the scrotal raphe. The abdomen ultrasound was normal, no genitourinary anomalies were detected.

Based on the clinical examination, the diagnosis of canal-like median raphe cyst was suspected. In this case the cyst was complicated by infection. Considered the poor respond to antibiotic therapy and the symptoms worsening, a surgical treatment was decided, and the lesion was incised to drain the purulent liquid. The wound was medicated with chlorhexidine and oral original author(s) and the source, provide a link to the Creative Commons licence, and indicate if changes were made. The images or other third party material in this article are included in the article's Creative Commons licence, unless indicated otherwise in a credit line to the material. If material is not included in the article's Creative Commons licence and your intended use is not permitted by statutory regulation or exceeds the permitted use, you will need to obtain permission directly from the copyright holder. To view a copy of this licence, visit http://creativecommons.org/licenses/by/4.0/. The Creative Commons Public Domain Dedication waiver (http://creativeco mmons.org/publicdomain/zero/1.0/) applies to the data made available in this article, unless otherwise stated in a credit line to the data. 


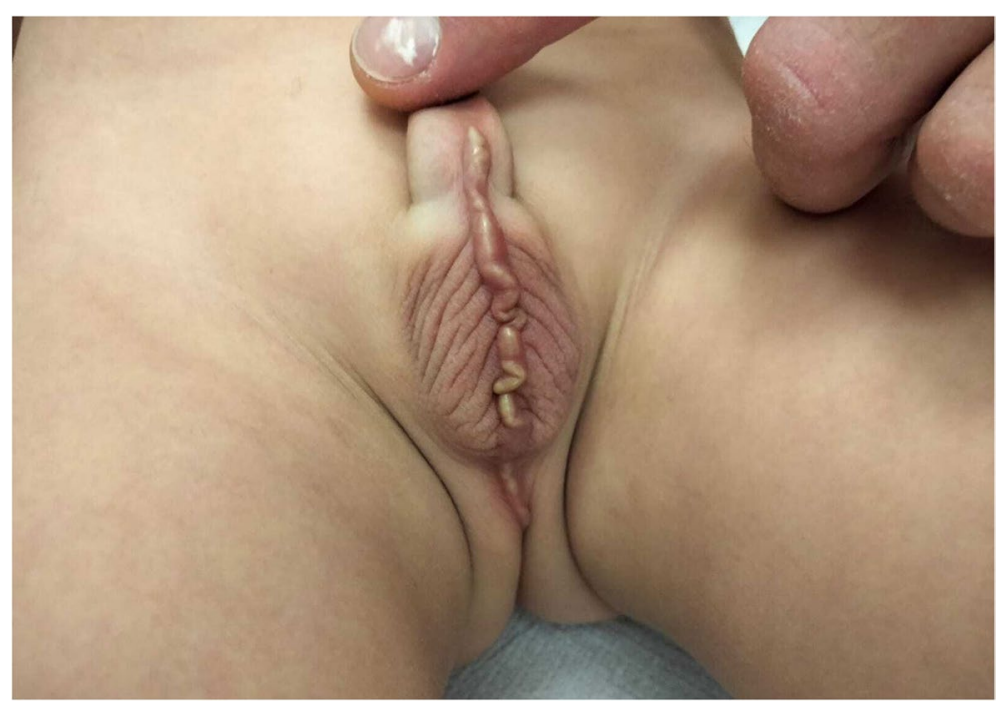

Fig. 1 Serpiginous lesion extended for $4 \mathrm{~cm}$ from the basis of the penis all along the scrotum in the midline

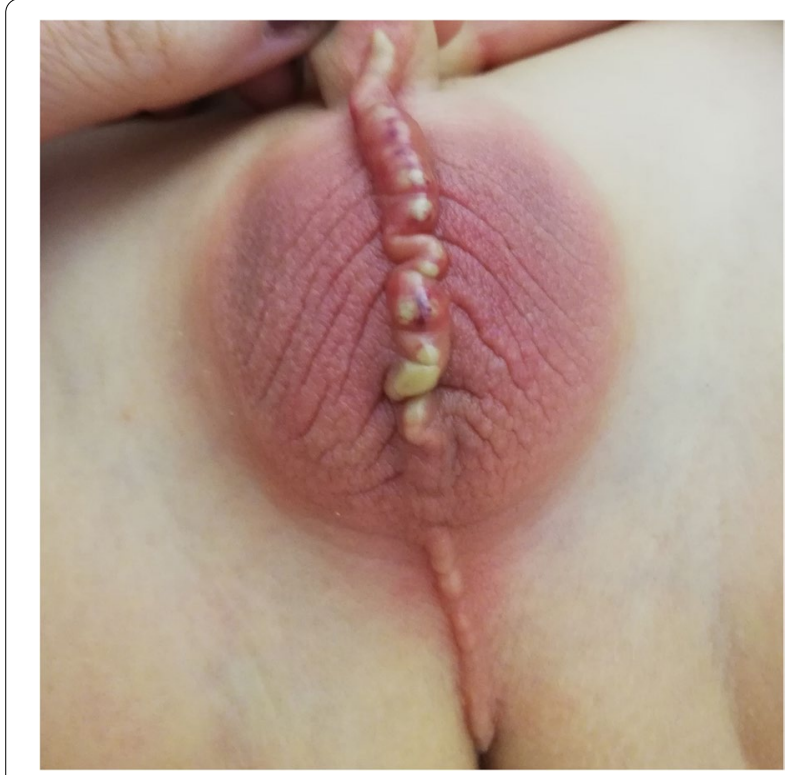

Fig. 2 Scrotum cellulitis with pus secretion from the lesion

antibiotic therapy with amoxicillin/clavulanic acid was continued for 10 days. Serratia Marcescens was isolated from the cultures, but unfortunately the material was not considered sufficient for histopathological confirmation. Symptoms completely resolved after treatment. The patient underwent to surgery follow up and no other interventions required. However, Serratia Marcescens is one of the most common pathogens responsible of infection in children with chronic granulomatous disease (CGD), especially in the genitourinary system.
Therefore, the assessment of nicotinamide adenine dinucleotide phosphate (NADPH) oxidase function was performed. The complex's activity resulted intact excluding the immunodeficiency.

\section{Discussion}

Median raphe cysts are congenital uncommon lesions of the male genitalia developing along the median penile raphe from the meatus to the perineum [1]. They result from "tissue trappings" during the intra-uterine process of closure of urethral or genital folds [4]. Their clinical presentation is usually as a flesh to yellow solitary cyst, multiple cysts, or canal-like lesions in the ventral midline part of the penis and perineum [2]. The penile shaft is the most frequent location, followed by subcoronal, scrotal and perineal areas [1]. Cysts may sightly fluctuate in size throughout life [3]. Three histologic patterns have been described: 1) urethral type lined with pseudostratified columnar epithelium, such as the urothelium; (2) epidermoid type, with squamous stratified epithelium; and (3) mixed type, with both epitheliae. The urethral type is the most frequent (70.1\%) [4]. Their diagnosis in children is probably underreported with a median age at diagnosis of 24,6 years [5]. In fact, as cysts do not connect with urethra, up to $75 \%$ of cases are asymptomatic and infection is a rare complication $[2,6]$. Other described complications are the cysts rupture and sexual interference in adulthood $^{4 .}$ To prevent relapses and clinical symptoms, the majority of authors recommend surgical excision followed by primary closure ${ }^{1,5}$.

In case of infection, the most common organisms found in adults' patient are Neisseria gonorrhoeae, Trichomonas 
vaginalis and Staphylococcus aureus [6]. This case is unique in literature because the drainage liquid culture resulted positive for Serratia Marcescens, a common pathogen causing infections in patients affected by immunodeficiencies. In particular, chronic granulomatous disease (CGD) characterized by the defect in superoxide production, is the first immunodeficiency to rule out. Patients with CGD have an increased susceptibility to a narrow spectrum of pathogens including, beyond Serratia Marcescens, Staphylococcus aureus, Burkholderia cepacia complex, Nocardia species, Aspergillus species, Salmonella species and Mycobacterium tuberculosis. Most patient initially present within 5-years-old with lymphadenitis, abscesses especially of the liver and perianal region, pulmonary infections, osteomyelitis, and sepsis. Genitourinary and gastrointestinal systems are generally affected by granulomatous inflammation. The gold standard for diagnosing CGD is flowcytometric dihydrorhodamine (DHR) neutrophil respiratory burst assay to assess the nicotinamide adenine dinucleotide phosphate (NADPH) oxidase function $[7,8]$.

\section{Conclusion}

The diagnosis of median raphe cysts is clinical. The condition is more often asymptomatic in childhood, but infection or cyst rupture could occasionally occur. In these circumstances, the majority of authors recommend surgical excision.

Our case is the first described in literature in which cyst' liquid culture resulted positive for Serratia Marcescens. Every infection caused by this gram-negative organism should raise the suspicion of an underlining immunological disorder, and chronic granulomatous disease should always be excluded.

\section{Abbreviations}

CGD: Chronic granulomatous disease; DHR: Dihydrorhodamine; NADPH: Nicotinamide adenine dinucleotide phosphate.

\section{Acknowledgements}

The authors thank Martina Bradaschia for the English revision of the manuscript.

\section{Authors' contributions}

SR contributed in all parts of the study, concepted, and wrote the paper. $\mathrm{RD}$ contributed to clinical management and consulting and revised the manuscript. VD contributed to clinical management and consulting and revised the manuscript. EB contributed in all parts of the study and revised the manuscript. All authors read and approved the final manuscript.

\section{Funding}

Not applicable.

Availability of data and materials

Data sharing is not applicable to this article as no datasets were generated or analysed during the current study.

\section{Declarations}

\section{Ethics approval and consent to participate}

The Institute's IRB approved the study. Consent form was obtained.

\section{Consent for publication}

The authors declare that we have obtained the written consent from patient's parents for publication of the photographs in all forms and media.

\section{Competing interests}

The authors declare that they have no competing interests.

\section{Author details}

${ }^{1}$ Dipartimento Di Scienze Mediche e Chirurgiche e Della Salute, Università Degli Studi Di Trieste, Trieste, Italy. ${ }^{2}$ S. Maria Degli Angeli Hospital - Paediatric Department, Pordenone, Italy. Institute for Maternal and Child Health - IRCCS "Burlo Garofolo" - Paediatric Department, Trieste, Italy.

Received: 2 December 2021 Accepted: 7 February 2022

Published online: 03 March 2022

\section{References}

1. Matsuyama S, Matsui F, Yazawa K, Matsumoto F, Shimada K, Matsuoka K. Long-term Follow-up of Median Raphe Cysts and Parameatal Urethral Cysts in Male Children. Urology. 2017;101:99-103.

2. Patrizi A, Neri I, Lima M, Libri M, Gurioli C, Ravaioli GM. Congenital multiple median raphe cysts of the penis and scrotum. J Paediatr Child Health. 2019:55(11):1389-90.

3. Bayne EC, DeMarco RT, Wehry MA. Median Raphe Cyst of the Perineum. J Pediatr. 2020;216:236.

4. Krauel L, Tarrado X, Garcia-Aparicio L, Lerena J, Suñol M, Rodó J, Ribó JM. Median raphe cysts of the perineum in children. Urology. 2008;71(5):830-1.

5. Navalón-MonllorOrdoño-Saiz MV, Ordoño-Domínguez F, SabaterMarco V, Pallás-Costa Y, Navalón-Verdejo P. Median raphe cysts in men. Presentation of our experience and literature review. Actas Urol Esp. 2017:41:205-9.

6. Aarif Syed MM, Amatya B, Sitaula S. Median raphe cyst of the penis: a case report and review of the literature. J Med Case Reports. 2019:13:214.

7. Yu JE, Azar AE, Chong HJ, Jongco AM 3rd, Prince BT. Considerations in the Diagnosis of Chronic Granulomatous Disease. J Pediatric Infect Dis Soc. 2018;7(suppl 1):S6-11.

8. Roos D. Chronic granulomatous disease. Br Med Bull. 2016;118(1):50-63.

\section{Publisher's Note}

Springer Nature remains neutral with regard to jurisdictional claims in published maps and institutional affiliations.
Ready to submit your research? Choose BMC and benefit from:

- fast, convenient online submission

- thorough peer review by experienced researchers in your field

- rapid publication on acceptance

- support for research data, including large and complex data types

- gold Open Access which fosters wider collaboration and increased citations

- maximum visibility for your research: over 100M website views per year

At $\mathrm{BMC}$, research is always in progress.

Learn more biomedcentral.com/submissions 